Revista do Departamento de Geografia
Universidade de São Paulo
www.revistas.usp.br/rdg
Volume Especial - XVII SBGFA / I CNGF (2017)

\title{
Antropogeomorfologia e Problemática Erosiva em Área Rural Degradada, Marabá Paulista (SP)
}

\section{Anthropogeomorphology and Erosive Problems in a Degraded Rural Area, Marabá Paulista (SP)}

Felipe Augusto Scudeller Zanatta

Universidade Estadual Paulista Julio de Mesquita Filho (UNESP/Rio Claro)

felipeasz@hotmail.com

Cenira Maria Lupinacci

Universidade Estadual Paulista Julio de Mesquita Filho (UNESP/Rio Claro)

Cenira@rc.unesp.br

Marcos Norberto Boin

Universidade Federal da Grande Dourados

Boinmar@hotmail.com

Rodrigo Braga Moruzzi

Universidade Estadual Paulista Julio de Mesquita Filho (UNESP/Rio Claro)

Recebido (Received): 18/03/2017

Aceito (Accepted): 02/06/2017

rmoruzzi@rc.unesp.br

\begin{abstract}
Soil erosion is a problem of global dimensions and causes losses of natural resources, arable land and soil productivity, which affect all society, but above all, farmers and the economy. This paper aims to understand the anthropic interference in the erosive dynamics of a basin with two gullying processes, in the city of Marabá Paulista (SP). For it, we used geomorphology and land cover maps in a scale of 1: 10,000 for the scenarios of 1963, 1979, 1997, 2010 and 2015. The mapped information were quantified according to the spatial nature of each variable and put together through the Pearson's Correlation Coefficient ( $p$ ). The result was the identification of a strong-to-perfect positive correlation between pastures and erosive processes, and between these processes with agricultural terraces and containment basins, since infiltration supplies the gully in the area, in order to increase the flow of water in the thalweg and promote landslip in the sides and head of this erosive way, dynamizing the slopes, mainly those ones with overgrazing. There for, we understood that conservation techniques, when are not followed by changes, in land use, that are appropriate to the physical characteristics and the active processes, have their function perverted, contributing to the evolution of the erosive processes.
\end{abstract}

Keywords: Erosive Dynamics; Pearson's Correlation Coefficient (p); Gully; Conservation Techniques.

Palavras-chave: Dinâmica Erosiva; Coeficiente de Correlação Pearson ( $p)$; Voçoroca; Técnicas Conservacionistas. 


\section{INTRODUÇÃO}

A erosão do solo representa um problema de dimensões globais, devido, sobretudo, ao uso inadequado dos terrenos para fins agropastoris. De acordo com estudo da Food and Agriculture Organization of the United Nations (FAO, 2015), 33\% dos solos em uso no mundo encontram-se degradados. Nessas áreas, destinam-se recursos para controlar o processo, no entanto, quando não se compreende o comportamento do fenômeno, mesmo com investimento em distintas técnicas, por vezes, acaba-se por intensificar a erosão, resultando em mais prejuízos.

O fenômeno erosivo constitui-se em um processo da natureza que pode ocorrer independente da ação humana. A forma erosiva indica estado de instabilidade do sistema natural, provocado quando há alteração de um ou mais componentes do ambiente e no modo como os elementos se inter-relacionam, de maneira que a energia que entra no sistema encontre alterações em sua de dissipação. Nessa perspectiva, o desenvolvimento do processo erosivo indica a busca do sistema ambiente por um novo arranjo após a perturbação, uma organização dos componentes do sistema que possibilite a dissipação da energia sem provocar alterações funcionais, e, consequentemente, estruturais, cessando o efeito da erosão.

A ação humana, quando incompatível com as características naturais do ambiente em que se estabelece, proporciona as condições para origem e desenvolvimento de processos erosivos, uma vez que altera um ou mais elementos desconsiderando sua importância para organização daquele sistema.

No intuito de compreender a problemática erosiva, considerando a ação humana e a formação e desenvolvimento dos processos erosivos em uma perspectiva do tempo histórico, nesse artigo, foi selecionada como área de estudo uma bacia hidrográfica localizada na área rural do Município de Marabá Paulista, a W do estado de São Paulo (Figura 1).

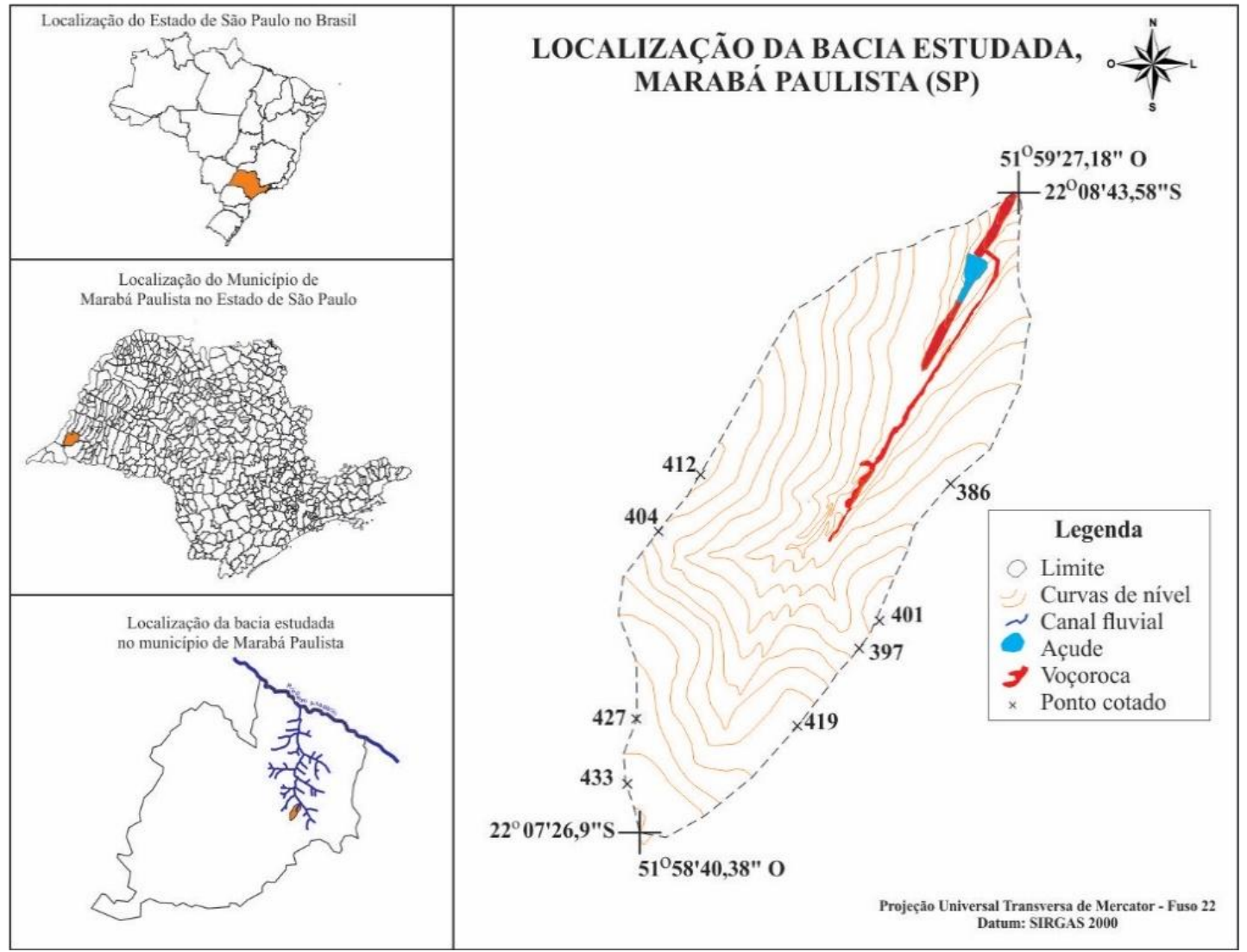

Figura 1: Localização da Bacia estudada.

O objeto do estudo foi selecionado em virtude de um extenso processo de voçorocamento que dá origem a um canal antropogênico, o qual escoa no percurso de antiga estrada rural, situação que se registra com frequência em Marabá Paulista (SP). Assim, avalia-se o efeito das interferências antrópicas (uso da terra) e das técnicas conservacionistas utilizadas, na dinâmica erosiva da bacia estudada. 
Localizada sobre litologias areníticas do Grupo Bauru, os solos da bacia estudada são predominantemente de textura arenosa em todo perfil (CARVALHO et al., 1997), submetidos a um clima tropical úmido, com chuvas intensas e/ou prolongadas, sobretudo na primavera e verão (BOIN, 2000). Inserida no contexto de ocupação do Oeste Paulista, iniciado no final do século XIX e início do século XX (MONBEIG, 1984), o uso da terra se estabeleceu de maneira predatória e descontextualizada em relação às especificidades do ambiente. A bacia em questão, desde a década de 60 , não apresenta vegetação nativa, sendo, em sua totalidade, submetida à racionalidade econômica da produção agropecuária até os dias atuais.

Nessa área, mapeou-se, em escala 1: 10.000, as feições geomorfológicas, seguindo orientações de Tricart (1965), nos cenários de 1963, 1979 1997, 2010 e 2015. Nesses anos, também foram mapeados o uso e cobertura superficial da terra, de acordo com a proposta do Instituto Brasileiro de Geografia e Estatística (IBGE, 2006). Os mapeamentos foram realizados no programa ArcGis 9.2, por meio do qual levantou-se os dados quantitativos das feições geomorfológicas e do uso e cobertura superficial da terra. Esses dados, tabulados no programa Microsoft Excel®, foram trabalhados estatisticamente através do Coeficiente de Correlação de Pearson (CCP), de modo a indicar o grau de relacionamento entre as variáveis quantificadas, procurando compreender a dinâmica erosiva e a organização funcional do sistema.

\section{MATERIAIS E TÉCNICAS CARTOGRÁFICAS}

O trabalho cartográfico iniciou-se com a digitalização das cartas topográficas desenvolvidas pelo Instituto Geográfico e Cartográfico do Estado de São Paulo (IGC), em escala 1:10.000, extraindo das Folhas SF-22-Y-B-II-1-SO-A，SF-22-Y-B-I-2-SE-B，SF-22-Y-B-II-1-NO-E，SF-22-Y-B-I-2-NE-F， os dados de topografia, como curvas de nível e os pontos cotados, com seus respectivos valores altimétricos, vetorizados no programa ArcGis 9.2. Todos os mapeamentos foram convertidos para a escala da carta base, 1:10.000.

Posteriormente as fotografias aéreas dos anos de 1963 (Levantamento Fotogramétrico do Estado de São Paulo), escala 1:25.000, 1979 (Terrafoto S.A. - Atividades de Aerolevantamentos, 1978/9), escala 1: 20.000, e 1997 (Aerolevantamento Presidente Venceslau e áreas correlatas), 1:35.000, foram trabalhadas em estereoscopia digital, no programa StereoPhotoMaker, enquanto as ortofotos de 2010 (Projeto de atualização cartográfica do Estado de São Paulo - Mapeia São Paulo), em escala 1:10.000, e a imagem orbital do satélite Quickbird de 2013 foram avaliadas por fotointerpretação, sem estereoscopia, e reambuladas de campo.

Para a elaboração das cartas geomorfológicas utilizou-se a metodologia de Tricart (1965), com algumas adaptações de simbologias de Verstappen e Zuidan (1975), identificando: formas erosivas (formas que indicam erosão laminar, sulcos, ravina e voçoroca); feições de drenagem (fundo de vale plano); e modelado antrópico (canal antropogênico, terraços agrícolas, bacias de contenção, açudes e estradas rurais). Já para os dados de uso e cobertura superficial da terra, utilizaram-se as orientações de IBGE (2006), mapeando as áreas com: reflorestamento; silvicultura; cultura temporária; pasto; pasto sujo e vegetação de área úmida.

Após a identificação e mapeamento das feições geomorfológicas e do uso e cobertura superficial da terra nos cinco cenários avaliados, essas informações foram levantadas de forma quantitativa, sendo os dados de uso da terra trabalhados em porcentagem de área; já os dados geomorfológicos foram avaliados de acordo com sua natureza espacial, a saber: marcas que indicam erosão laminar, voçoroca, terraços agrícolas e açudes em área, em \%; bacias de contenção, sulcos e ravinas em número; estrada rural, canal fluvial com fundo de vale plano e canal antropogênico em extensão, em km.

Esses dados quantitativos foram analisados através do Coeficiente de Correlação de Pearson (CCP). Para tanto, no programa Microsoft Excel, elaborou-se uma tabela contendo nas colunas os anos, os dados de uso da terra e de geomorfologia, enquanto as linhas a área, número ou extensão das variáveis em cada cenário analisado (1963, 1979, 1997, 2010 e 2015). Os resultados foram marcados com cores que variam de verde (intensidade de correlação positiva), vermelho (intensidade de correlação negativa) e branco (correlação nula).

Ao final, foi realizada a remoção dos dados que não apresentavam significância espacial, como, por exemplo: as correlações entre informações de uso da terra, optando-se, ainda, pela exclusão das informações de silvicultura e reflorestamento que abrangem áreas muito pequenas. Foram ainda discriminadas as informações que oscilam em faixas diferentes ao longo dos anos, analisadas de forma separada. 


\section{RESULTADOS E DISCUSSÕES}

A área estudada, desde 1963 não apresenta vegetação do tipo nativa, portanto, desde o primeiro ano analisado, a bacia encontra-se em sua totalidade vinculada à racionalidade estritamente econômica para produção agrícola, sobretudo para pastagem, presente na maioria da bacia em todos os cenários, com destaque para 1979 e 1997 (Tabela 1).

Tabela 1: Uso e cobertura superficial da terra ao longo dos cenários analisados. Área, em \%.

\begin{tabular}{r|r|r|r|r|r|r} 
Ano & Reflorestamento & Silvicultura & $\begin{array}{c}\text { Cultura } \\
\text { temporária }\end{array}$ & Pasto & $\begin{array}{c}\text { Pasto } \\
\text { sujo }\end{array}$ & $\begin{array}{r}\text { Vegetação } \\
\text { de área } \\
\text { úmida }\end{array}$ \\
\hline $\mathbf{1 9 6 2}$ & 0,00 & 4,01 & 30,03 & 65,83 & 0,00 & 0,00 \\
\hline $\mathbf{1 9 7 9}$ & 0,00 & 0,00 & 0,00 & 100 & 0,00 & 0,00 \\
\hline $\mathbf{1 9 9 7}$ & 0,30 & 0,00 & 0,00 & 96,19 & 2,67 & 0,00 \\
\hline $\mathbf{2 0 1 0}$ & 0,63 & 0,00 & 51,17 & 44,11 & 3,39 & 0,18 \\
\hline $\mathbf{2 0 1 5}$ & 0,63 & 0,00 & 51,17 & 42,11 & 5,39 & 0,18 \\
\hline
\end{tabular}

Mudanças significativas ocorrem a partir de 2010, quando as empresas sucroalcooleiras se expandem para a região, arrendando metade dos terrenos da bacia para cultivo de cana-de-açúcar, apresentada como cultura temporária na Tabela 1, a qual passa a ocupar 51,17\% da área. Em campo, no ano de 2015, constatou-se que, devido ao término da concessão antes do período da safra, essa cultura encontra-se abandonada, sem manejo adequado, com a cana-de-açúcar queimada, utilizada como pasto.

$\mathrm{Na}$ condição de toda cobertura superficial dos terrenos determinada pela ação antrópica desde o primeiro ano avaliado, identificaram-se formas erosivas em estágios de desenvolvimento avançado em todos os cenários, as quais aumentaram em área e número ao longo dos anos (Tabela 2).

Tabela 2: Feições geomorfológicas dos cenários analisados.

\begin{tabular}{|l|r|r|r|r|r|}
\hline & $\mathbf{1 9 6 2}$ & $\mathbf{1 9 7 9}$ & $\mathbf{1 9 9 7}$ & $\mathbf{2 0 1 0}$ & $\mathbf{2 0 1 5}$ \\
\hline Marcas que indicam erosão laminar (área, em \%) & 13,08 & 74,82 & 97,77 & 82,60 & 98,00 \\
\hline Sulco (número) & 9,00 & 13,00 & 33,00 & 43,00 & 54,00 \\
\hline Ravina (número) & 7,00 & 17,00 & 17,00 & 65,00 & 65,00 \\
\hline Voçoroca (área, em \%) & 0,32 & 1,06 & 1,04 & 1,26 & 1,37 \\
\hline Canal fluvial com fundo de vale plano (extensão, km) & 0,55 & 0,56 & 0,57 & 0,53 & 0,53 \\
\hline Canal antropogênico (extensão, km) & 0,00 & 0,56 & 0,71 & 0,89 & 1,11 \\
\hline Terraços agrícolas (área, em \%) & 0,00 & 0,00 & 49,00 & 79,28 & 79,28 \\
\hline Bacias de contenção (número) & 0,00 & 0,00 & 0,00 & 57,00 & 57,00 \\
\hline Estrada rural (extensão, km) & 5,01 & 5,25 & 5,25 & 6,86 & 6,86 \\
\hline Açude (área, em \%) & 0,00 & 0,00 & 0,47 & 0,47 & 0,47 \\
\hline
\end{tabular}

De 1997 para 2010, embora diversas técnicas conservacionistas tenham sido implementadas para conter os processos erosivos de vertentes, observa-se um aumento significativo destas, sobretudo em meio às pastagens (Figura 2). 


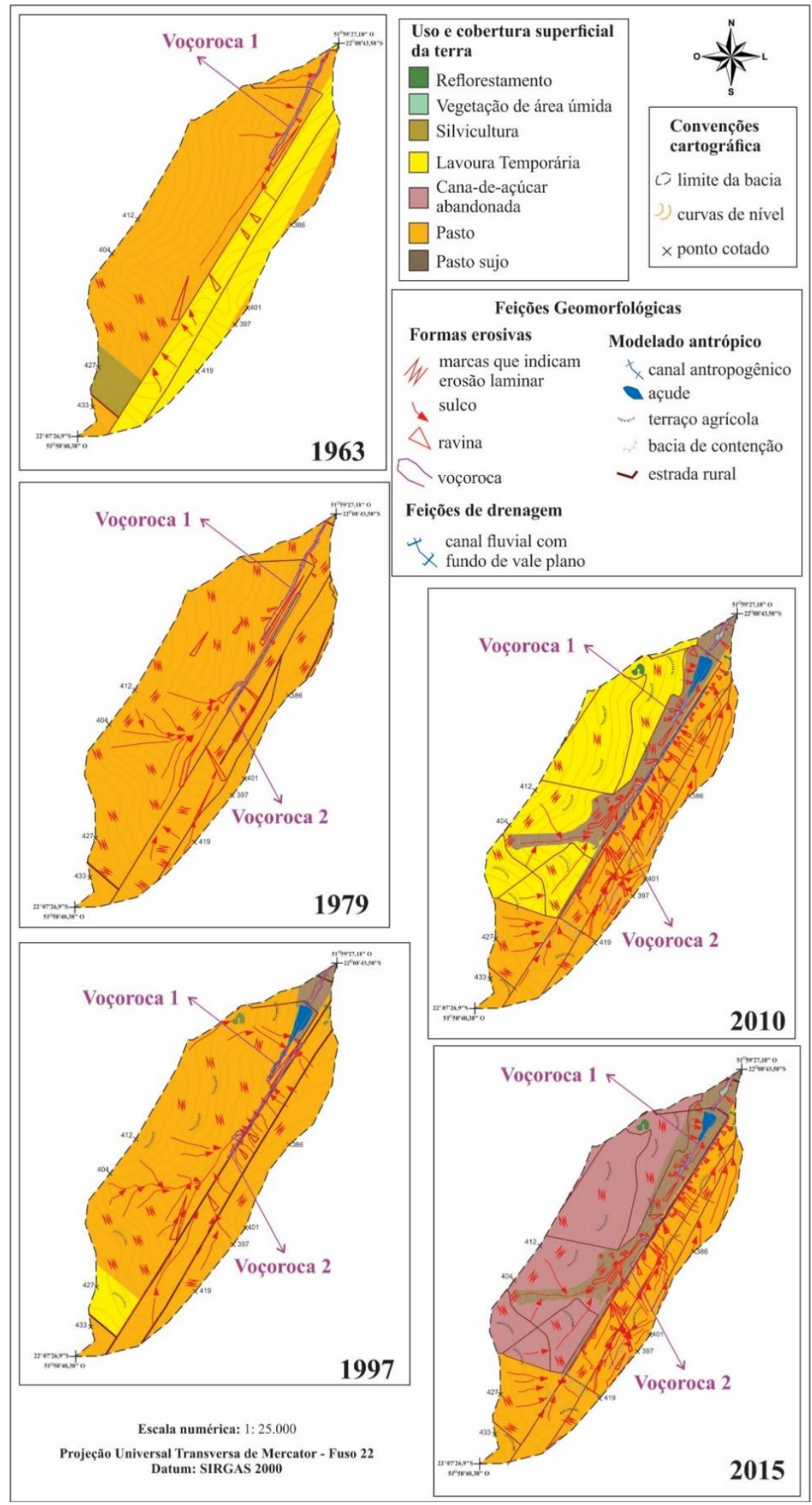

Figura 2: Uso e cobertura superficial da terra e feições geomorfológicas nos cenários de 1963, 1979, 1997, 2010 e 2015.

$\mathrm{Na}$ voçoroca 1, que se desenvolve em canal com fundo plano desde o primeiro ano analisado, o médio curso do canal foi represado em 1997 para conter o fluxo de água, e, consequentemente, o processo erosivo. Como efeito, nos anos seguintes, 2010 e 2015, constata-se a colonização por vegetação de área úmida no talvegue da forma erosiva, ao mesmo tempo que surgem ravinas e sulcos na cabeceira e em suas margens, a jusante e montante do represamento. Já a voçoroca 2, identificada a partir do segundo ano analisado, em 1979, tem seu escoamento direcionado à estrada rural, originando um canal antropogênico. Esse canal passa a captar a água que escoa da alta e média bacia e das vertentes à L da baixa bacia, de modo 
que a erosão se ramifica com maior intensidade nas vertentes a L, onde predomina o pasto desde 1979, enquanto nas margens a $\mathrm{O}$, a erosão evolui com menor intensidade, devido, sobretudo, ao cercamento das margens das ravinas e voçorocas, de dezenas de bacias de contenção em setores onde ocorrem sulcos e dos reparos periódicos nos terraços agrícolas em área de cultivo de cana-de-açúcar (Figura 2).

Dessa forma, ao longo das mudanças apresentadas nos cenários avaliados, constatou-se a intensidade de correlação positiva entre o uso da terra, as técnicas conservacionistas e as formas erosivas (Tabela 3).

Tabela 3: Coeficiente de Correlação de Pearson (CCP) entre variáveis de uso da terra e geomorfologia ao longo dos cenários de 1963, 1976, 1997, 2010 e 2015

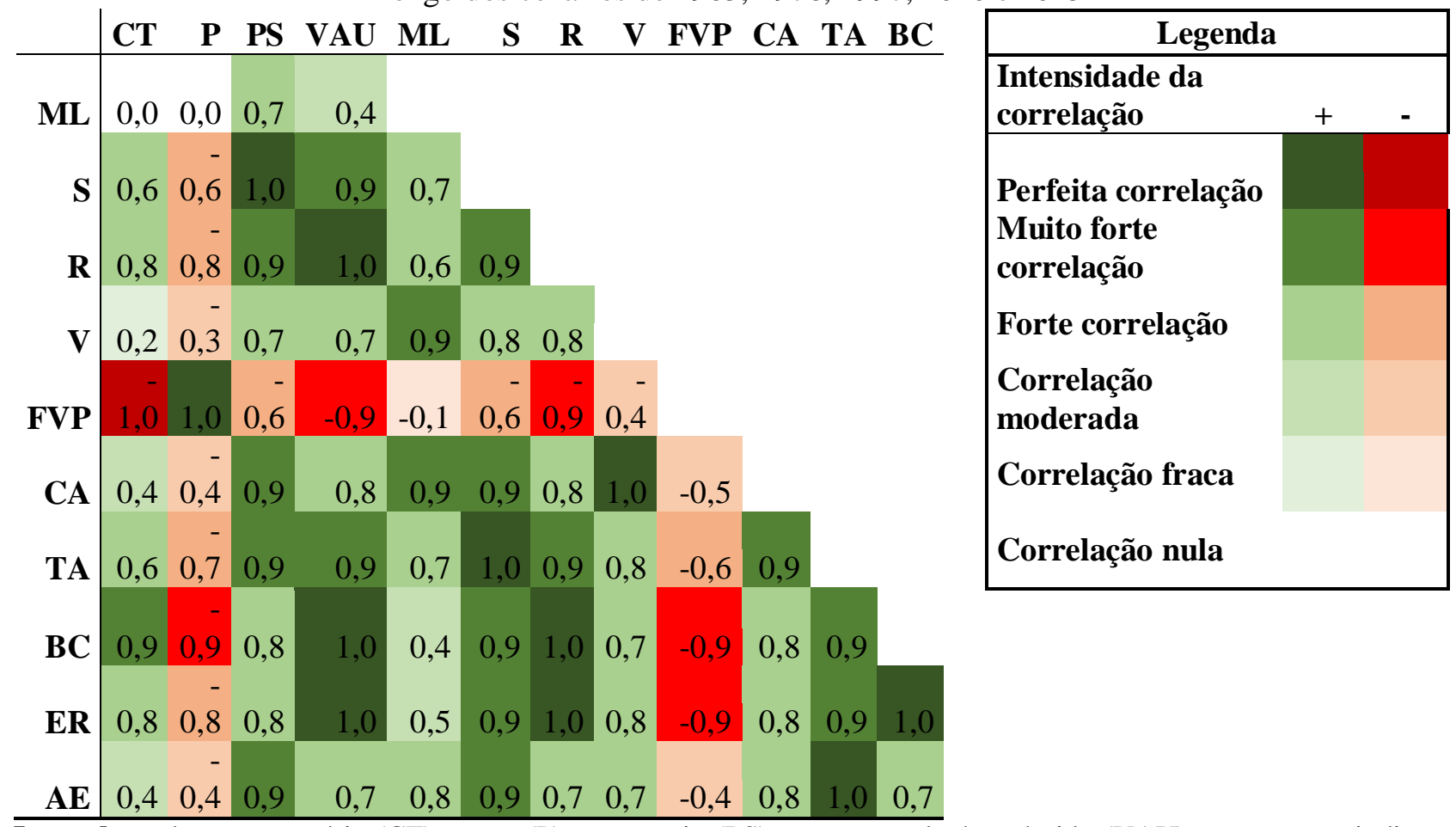

Legenda: cultura temporária (CT); pasto (P); pasto sujo (PS); vegetação de área úmida (VAU); marcas que indicam erosão laminar (ML); sulcos (S); ravina (R); voçoroca (V); canal fluvial com fundo de vale plano (FVP); canal antropogênico (CA); terraço agrícola (TA); bacias de contenção (BC); estrada rural (ER) e açude (AE).

Quanto as mudanças promovidas na cobertura superficial no ano de 2010, constatou-se que 51,17\% das áreas com pasto foram destinadas ao cultivo de cana-de-açúcar (Tabela 1). Em relação à essa cobertura, verifica-se a correlação nula com as marcas que indicam erosão laminar (Tabela 3), uma vez que durante o cultivo são realizados constantes reparos dos terraços agrícolas, no entanto, a intensidade de correlação é positiva com os fenômenos lineares, sendo correlação forte com os sulcos e ravinas e fraca com a voçoroca (Tabela 3). Como observado na Figura 2, o processo não atinge nível de ravinamento sob essa cobertura, mas constata-se presença de sulcos e marcas que indicam erosão laminar, apesar da correlação nula em contexto mais amplo de análise. Isso ocorre devido à manutenção constante dos terraços agrícolas, uma vez a cana-de-açúcar oferta pouca proteção ao solo no período de entressafra, momento que coincide com as primeiras chuvas após o inverno. Assim, segundo pesquisas já divulgadas (LEPSCH et al., 1983; MENDES, 1993) essa cobertura é menos eficiente que as gramíneas utilizadas para pastagens, de modo que muitas das feições que surgem durante os períodos chuvosos são corrigidas com carreadores, impossibilitando que essas sejam cartografadas.

A intensidade da correlação negativa entre o pasto e todas as formas erosivas decorre da redução dessa cobertura superficial a partir de 2010, enquanto as formas erosivas continuam aumentando, embora, em sua maioria, sejam em áreas de pasto. Assim, ao avaliar a correlação entre as pastagens e as formas erosivas, nos três primeiros anos (1963, 1979 e 1997), em que o pasto predomina e as voçorocas surgem, aferiu-se a perfeita correlação com as formas erosivas mais desenvolvidas (ravinas e voçorocas), muito forte correlação com marcas de erosão laminar e moderada correlação com os sulcos (Tabela 4). 
Tabela 4: Coeficiente de Correlação de Pearson (CCP) entre pasto e formas erosivas nos cenários de 1963, 1979 e 1997.

\begin{tabular}{c|rrrr} 
& $\begin{array}{r}\text { Marcas que } \\
\text { indicam erosão } \\
\text { laminar }\end{array}$ & Sulco & Ravina & Voçoroca \\
\hline Pasto & 0,9 & 0,5 & 1,0 & 1,0 \\
\hline
\end{tabular}

\begin{tabular}{|l|}
\hline \multicolumn{1}{|c|}{ Legenda } \\
\hline $\begin{array}{l}\text { Intensidade de } \\
\text { correlação }\end{array}$ \\
\hline $\begin{array}{l}\text { Perfeita correlação } \\
\text { Muito forte correlação } \\
\text { Correlação moderada }\end{array}$ \\
\hline
\end{tabular}

Tais dados indicam que o pastoreio excessivo e contínuo em solos de textura arenosa promove o desencadeamento de processos areolares e lineares nas vertentes, de modo que o fenômeno, ainda, se desenvolva com intensidade, provocando na destruição da vertente.

A mesma situação de intensidade da correlação negativa ocorre ente os canais fluviais com fundo de vale plano e as demais variáveis, uma vez que essa feição de drenagem, em 1997, é reduzida em extensão quando ocorre o represamento no médio curso do canal, na medida que todas as demais variáveis aumentaram nos anos seguintes, exceto o pasto, com que apresenta correlação forte. Ao verificar a correlação existente entre as formas erosivas e o fundo de vale plano nos anos anteriores ao represamento, 1963 e 1979, identificou-se a perfeita correlação positiva entre as variáveis, uma vez que todo o percurso desse canal se encontrava no interior da voçoroca e este processo se ramificou em ravinas e sulcos, dinamizando os processos erosivos nas vertentes (Tabela 5).

Tabela 4: Coeficiente de Correlação de Pearson (CCP) entre canal fluvial com fundo de vale plano e formas erosivas nos cenários de 1963 e 1979.

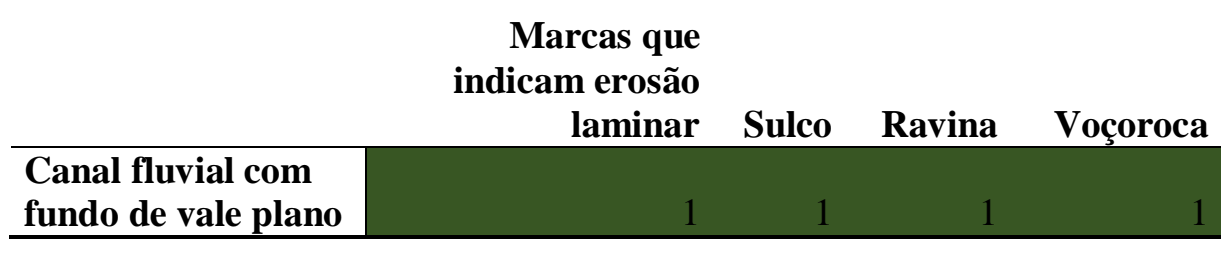

\begin{tabular}{|l|}
\hline \multicolumn{1}{|c|}{ Legenda } \\
\hline $\begin{array}{l}\text { Intensidade } \\
\text { da correlação }\end{array}$ \\
\hline $\begin{array}{l}\text { Perfeita } \\
\text { correlação }\end{array}$ \\
\hline
\end{tabular}

Em 1997 inicia-se o uso de terraços agrícolas em meio às pastagens e a construção de um açude no médio curso do canal em fundo plano com voçorocamento. No entanto, nos anos que seguem, 2010 e 2015, mesmo com as mudanças na atividade agropastoril, o cercamento das voçorocas e ravinas nas vertentes a $\mathrm{O}$, o aumento dos terraços agrícolas para 79,28\% dos terrenos da bacia e o uso de cinquenta e sete bacias de contenção em áreas que desenvolvem sulcos, houve concomitante ampliação de todos os processos erosivos (Tabela 2), registrando-se correlação positiva entre as técnicas utilizadas e todas as formas erosivas (Tabela 3).

Embora os terraços agrícolas e as bacias de contenção tenham teoricamente a função de conter o fluxo de água e, portanto, impedir o desenvolvimento dos processos erosivos nas vertentes, quando da presença da voçoroca, tais técnicas apresentam efeito contrário, uma vez que, aumentando a infiltração de água em solos de textura arenosa em todo perfil, dinamiza a ação erosiva através de desbarrancamentos laterais e na cabeceira, com aumento de fluxo de água no talvegue da referida voçoroca. Essa evolução da voçoroca desestabiliza os terrenos, com os solos desgastados pelo uso contínuo, aumentando o número das demais feições erosivas (sulcos e ravinas) nas vertentes circunvizinhas (Tabela 2).

Esse processo foi aferido nas mudanças ocorridas nos dois últimos anos analisados: no cenário de 2010, a voçoroca que atinge a estrada rural, originando um canal antropogênico, não tinha força suficiente para escoar até o canal fluvial com fundo plano a jusante, infiltrando-se no solo arenoso em meio ao percurso; enquanto no cenário de 2015 ocorre aumento significativo do fluxo de água, de modo a escoar por toda estrada até atingir o canal a jusante do açude (Figura 3). Cabe destacar, que no dia 18 de outubro de 2016 (Figura 3B), as condições climáticas eram de um período seco. 


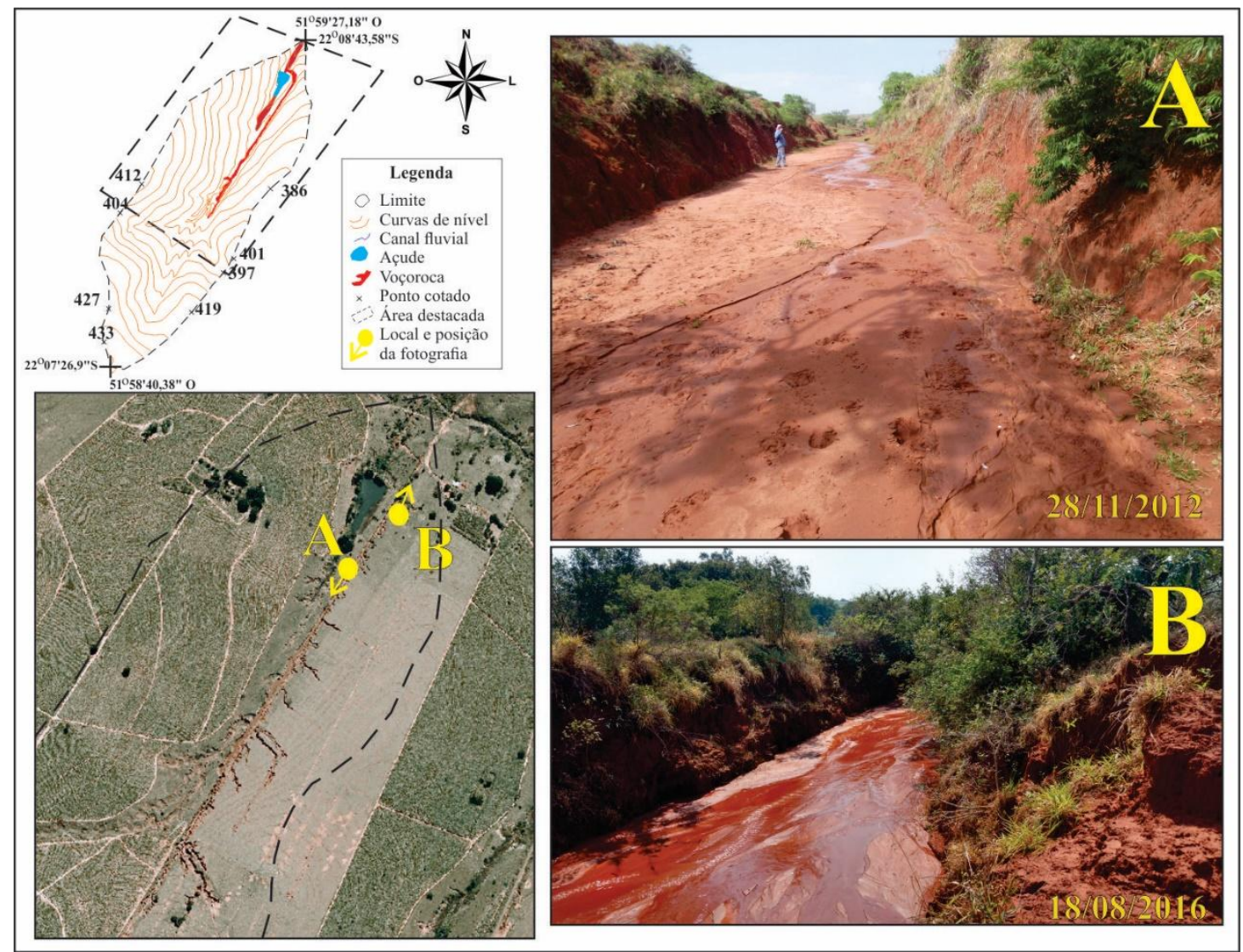

Figura 3: Fluxo de água na estrada rural atingida por voçorocamento em 28 de novembro de 2012 (1) e 18 de agosto de 2016 (2).

A fragilização dos solos, com o uso contínuo para pastoreio, que compacta os horizontes superficiais e dinamiza o desbarrancamento das formas lineares nas vertentes a $\mathrm{E}$, e a queimada da cana-de-açúcar abandonada, que contribui para desestruturação dos horizontes superficiais nas vertentes a $\mathrm{W}$, aliadas ao aumento de fluxo de água no talvegue da erosão, promovido pelas técnicas conservacionistas, contribuem para que o fenômeno erosivo continue ativo e se desenvolvendo.

\section{CONSIDERAÇÕES FINAIS}

Os dados demonstram que as técnicas conservacionistas utilizadas para controlar o fenômeno erosivo, em uma bacia com dois processos de voçorocamento, contribuíram para potencializar a dinâmica erosiva na área, haja visto que o aumento dos terraços agrícolas e das bacias de contenção não reduziram o fenômeno, mas os intensificaram, promovendo o aumento do fluxo de água no talvegue da voçoroca e, consequentemente, o desenvolvimento dos processos lineares nas vertentes, principalmente à $\mathrm{L}$ em que o superpastoreio dos terrenos fragilizam os solos. Assim, a compreensão parcial do fenômeno acarreta em prejuízos, tanto na perda de recursos naturais, refletindo na diminuição da área agricultável, como de investimentos destinados a implementação de técnicas que não contribuem para conter os processos erosivos atuantes.

Como limitação do uso do Coeficiente de Correlação de Pearson (CCP) para análise junto a cartografia geomorfológica retrospectiva, constatou-se que algumas variáveis oscilam de forma distinta, não apresentando um comportamento linear ao longo do tempo, de modo que as feições erosivas tenham intensidade de correlação em intervalos negativos com o pasto, embora seja sobre predomínio desta cobertura que se desenvolvem as duas voçorocas presentes na bacia, em 1963 e 1979, e, embora reduzida a área em 2010 e 2015, seja nas vertentes a L em a voçoroca se ramifique com maior intensidade em sulcos e ravinas. Ademais, dada a natureza de sua formulação, a correlação medida entre pares de atributos quantitativos discretos limita a avaliação multivariada, característica de sistemas complexos. 


\section{REFERÊNCIAS}

BOIN, M. N. Chuvas e erosão no Oeste Paulista: uma análise climatológica aplicada. Rio Claro: UNESP. Tese (Doutorado) - Programa de Pós-Graduação em Geociências e Meio Ambiente, Instituto de Geociências e Ciências Exatas, Universidade Estadual Paulista, Rio Claro, 2000. 246p.

CARVALHO, W. A. (coord.). Levantamento semidetalhado dos solos da bacia do rio Santo AnastácioSP. Presidente Prudente, São Paulo: FCT-UNESP, 1997, vol. I e vol. II.

FOOD AND AGRICULTURE ORGANIZATION OF THE UNITED NATIONS (FAO). Status of the World's Soil Resources. Roma: Food and Agriculture Organization of the United Nations, 2015.

INSTUTO BRASILEIRO DE GEOGRAFIA E ESTATÍSTICA (IBGE). Manual técnico de uso da terra. Rio de Janeiro: IBGE, 2006.

LEPSCH, I. F.; BELLINAZZI Jr., R.; ESPINDOLA, C. R. Manual para levantamento utilitário do meio físico e classificação de terras no sistema de capacidade de uso. $4^{\mathrm{a}}$ aproximação. Campinas: Sociedade Brasileira de Ciência do Solo, 1993.

MENDES, I. A. A dinâmica erosiva do escoamento pluvial na bacia do córrego Lafon - Araçatuba-SP. São Paulo: USP. Tese (Doutorado) - Programa de Pós-Graduação em Geografia (Geografia Física). Faculdade de Filosofia, Letras e Ciências Humanas, Universidade de São Paulo, São Paulo, 1993.

MONBEIG, P. Pioneiros e Fazendeiros de São Paulo. São Paulo: HUCITEC, 1984.

TRICART, J. Principles et méthodes de la géomorphologie. Paris: Maisson, 1965.

VERSTAPPEN, H. T.; ZUIDAN, R. A. ITC system of geomorphological survey. Netherlands: Manuel ITC. Textbook, Vol. VII, Chapter VII, 1975. 